\title{
A Predictive Model for Mining Opinions of an Educational Database Using Neural Networks
}

\author{
M R Narasinga Rao ${ }^{1}$, Deepthi Gurram², Sai Mahathi Vadde ${ }^{3}$, Sathish Tallam ${ }^{* 4}$, \\ N. Sai Chand ${ }^{5}$, L. Kiran ${ }^{6}$ \\ Department of Computer Science, K L University, Guntur, Andhra Pradesh, India \\ Email: manda.ramanarasingarao@gmail.com ${ }^{1}$, deepug2110@gmail.com² ${ }^{2}$, sathish.thallam@gmail.com ${ }^{4}$
}

\section{Article Info}

Article history:

Received Apr 14, 2015

Revised Jun 21, 2015

Accepted Jul 2, 2015

\section{Keyword:}

Backpropagation algorithm

Multilayer perceptron

Neural network

Normalized system error

Performance analysis

Prediction

\begin{abstract}
Assessing the performance of an educational institute is a prime concern in an educational scenario. Educational Data Mining (EDM) considers several tasks originated from an educational context. One of the tasks identified is providing feedback for supporting instructors, administrators, teachers, course authors in decision making and thereby enable them to take appropriate remedial action. In this research, we have developed a prototype Neural Network Model which is trained to predict the performance of an educational institution. A Multilayer Perceptron Neural Network (MLP) model had been developed for this proposed research. The network is trained by back propagation algorithm. Data was obtained from a well-defined questionnaire consisting of 14 questions in the domains namely Academic Schedule, International Exposure, Jobs and Internship, Quality of the college, and Life at Campus. The results of these questions have been taken as inputs and performance of the institute has been considered as the output. To, validate the results generated by the network, statistical techniques have been used for the purpose. In this proposed research performance of an educational institution has been predicted. The results generated by the Neural Network and the statistical techniques have been compared in this research and it is observed that, both the methods have generated accurate results. The results have been considered based on the Normalized System Error (NSE) values of the network. A prototype Neural Network model has been developed to assess the performance of an educational institution.
\end{abstract}

Copyright (C) 2015 Institute of Advanced Engineering and Science. All rights reserved.

\section{Corresponding Author:}

Deepthi Gurram,

Departement of Computer Science \& Engineering,

KL University,

Vaddeswaram, Guntur (Dt), Andhra Pradesh, India.

Email: deepug2110@gmail.com

\section{INTRODUCTION}

There are increasing research interests in using data mining in educational context. This field is called educational data mining concerned with the development of methods that extracts knowledge from educational data. Educational Data Mining (EDM) is an application to analyze the types of data in educational context [1]. Many relevant studies have been carried out in educational data mining up to date [2]. A number of data mining techniques have been developed for educational purposes. A model based on decision tree had been employed to evaluate the student performance for classification task [3]. A Regression model using statistical approach has been developed in educational data mining [4]. A survey has been made on the application of data mining in learning management systems [5]. A more versatile data mining tool has been developed to suggest career options for students, to improve student performance, overcoming the problem of low grade students, and also for finding the violent behavior of the students [6] [7]. DM 
techniques have been employed in different domains to produce different kinds of reports for analysis purposes [8]. Application of DM in educational context is different in educational context compared to other domains [9]. There has been increasing interest in the application of DM in educational context [10]. Association rule mining has been used to confront the problem of continuous feedback in the educational process [11]. Relationship between learning behavior pattern for collaborative learning has been done [12]. DM techniques like temporal DM, learning decomposition, and logistic regression has been used to describe and predict student behavior and to evaluate the progress in relation to learning outcomes [13] [14]. In this proposed research, we would like to apply Neural Network model to assess the performance of the educational institute. The results of which have been compared with the statistical techniques.

\section{RELATED WORK}

An Educational Instrument is used for collecting the feedback was used in this research. The responses from different educational institutes had been considered in this research. The questions from feedback are related to different areas like Academic Schedule, International Exposure, Jobs and Internship, Quality of the college, and Life at Campus is prepared for this purpose. The responses are obtained on a 10 point scale as follows:

Excellent (10), Very Good (08), Good (06), Satisfactory (04), Unsatisfactory (02). The feedback from the students for the above questionnaire has been taken as input for the model and the average rating for each row is calculated for this purpose and is taken as the output of the model.

A Multi-layer Perceptron (MLP) network model with back-propagation algorithm has been used in this current research. The inputs along with the weighted sum and bias term are passed to the activation level through the transfer function to produce the actual output of the network. The units are arranged in layered feed forward neural networks. The schematic representation of feed forward back-propagated neural networks with 14 inputs with one hidden layer consisting of 9 neurons and 1 output unit in the output layer is given in Figure 1. The sigmoidal transfer function is chosen such that the algorithm requires a response function with a continuous, single valued with first derivative existence.

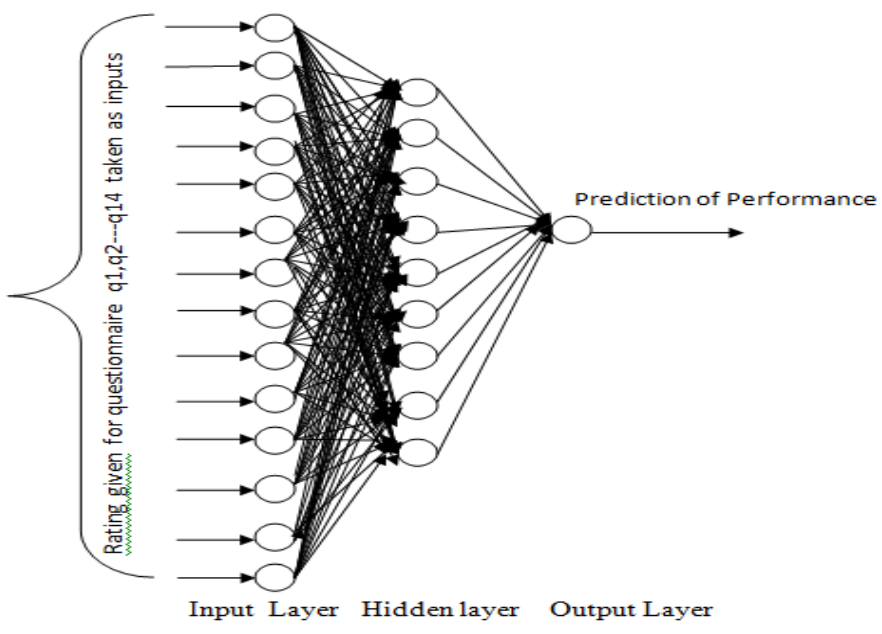

Figure 1. Feed Forward Neural Network

The operation of the typical MLP with back propagation algorithm is as follows. The operation of the typical back propagation network occurs as follows. [15]

1) After presenting input data to the input layer, information propagates through the network to the output layer (forward propagation). During this time input and output states for each neuron will be set.

$\mathrm{xj}[\mathrm{s}]=\mathrm{f}(\mathrm{Ij}[\mathrm{s}])=\mathrm{f}(\Sigma($ wij[s] $* \mathrm{xi}[\mathrm{s}-1])) \mathrm{i}[15]$

Where $x j[s]$ - Denotes the current input state of the jth neuron in the current $[\mathrm{s}]$ layer.

$\mathrm{Ij}[\mathrm{s}]$ - Denotes the weighted sum of inputs to the jth neuron in the current layer[s].

$\mathrm{f}$ is conventionally the sigmoid function. [15]

Wij [s] - denotes the connection weight between the ith neuron in the current layer [s] and jth neuron in the previous layer [s-1]. [15] 
2) Global error is generated based on the summed difference of required and calculated output values ofeach neuron in the output layer. The Normalized System error E (glob) is given by the Equation $\mathrm{E}(\mathrm{glob})=0.5 *(\mathrm{rk}-\mathrm{ok})^{2}$ and $(\mathrm{rk}-\mathrm{ok})$ denotes the difference of required and calculated output values. [15]

3) Global error is back propagated through the network to calculate local error values and delta weights for each neuron. Delta weights are modified according to the delta rule that strictly controls the continuous decrease of synaptic strength of those neurons that are mainly responsible for the global error. In this manner the regular decrease of global error can be assured.

$\mathrm{Ej}[\mathrm{s}]=\mathrm{xj}[\mathrm{s}] *(1.0-\mathrm{xj}[\mathrm{s}]) * \Sigma(\mathrm{ek}[\mathrm{s}+1] * \mathrm{wkj}[\mathrm{s}+1]) \mathrm{k}[15]$ Where $\mathrm{Ej}[\mathrm{s}]$ is the scaled local error of the jth neuron in the current layer $[\mathrm{s}]$ layer

$\Delta \mathrm{wji}[\mathrm{s}]=$ lcoef $*$ ej $[\mathrm{s}] * \mathrm{xi}[\mathrm{s}-1][15]$

Where $\Delta$ wji $[\mathrm{s}]$ - Denotes the delta weight of the connection between the current neuron and the joining neuron. Here, lcoef denotes the learning coefficient/ learning constant of the training parameters.

4) Synaptic weights are updated by adding delta weights to the current weights. [15]

\subsection{Analysis of Variance (ANOVA)}

Analysis of variance (ANOVA) is a general method of studying sampled-data relationships. The method enables the difference between two or more sample means to be analyzed, achieved by subdividing the total sum of squares. One way ANOVA purpose is to test for significant differences between class means, and this is done by analyzing the variances .Incidentally if we are only comparing two different means then the method is the same as the t-test for independent samples.

\section{RESULTS} the data set.

The following Table 1 provides the results obtained on applying one way ANOVA classification on

The One way analysis is calculated in three steps, first the sum of squares for all samples the within class and between classes. For each stage the degrees of freedom are obtained where df is the number of independent pieces that go in to estimate of a parameter. The second stage determines the sum of squares within the classes. Then the null hypothesis will be evaluated using significant differences values obtained.

Table 1. Results obtained on applying one way ANOVA classification on the data set

\begin{tabular}{|c|c|c|c|c|c|c|c|c|c|c|}
\hline & $\begin{array}{l}\text { Sum of squares } \\
\text { (Between the } \\
\text { groups) }\end{array}$ & $\begin{array}{c}\text { Sum of } \\
\text { squares } \\
\text { (With in the } \\
\text { groups) }\end{array}$ & Total & $\begin{array}{c}\text { Df } \\
\text { (Between } \\
\text { the groups) }\end{array}$ & $\begin{array}{l}\text { df } \\
\text { (With } \\
\text { in the } \\
\text { groups) }\end{array}$ & Total & $\begin{array}{c}\text { Mean } \\
\text { Square } \\
\text { (Between } \\
\text { the groups) }\end{array}$ & $\begin{array}{c}\text { Mean } \\
\text { Square } \\
\text { (With in the } \\
\text { groups) } \\
\end{array}$ & $\mathrm{F}$ & Sig \\
\hline Q1 & 2.31 & 1.332 & 3.642 & 7 & 92 & 99 & 0.33 & 0.014 & 22.79 & 0 \\
\hline Q2 & 2.309 & 2.609 & 4.918 & 7 & 92 & 99 & 0.33 & 0.028 & 11.633 & 0 \\
\hline Q3 & 2.052 & 1.898 & 3.95 & 7 & 92 & 99 & 0.293 & 0.021 & 14.207 & 0 \\
\hline Q4 & 2.419 & 2.236 & 4.654 & 7 & 92 & 99 & 0.346 & 0.024 & 14.217 & 0 \\
\hline Q5 & 3.069 & 2.472 & 5.54 & 7 & 92 & 99 & 0.438 & 0.027 & 16.316 & 0 \\
\hline Q6 & 2.777 & 2.769 & 5.546 & 7 & 92 & 99 & 0.397 & 0.03 & 13.183 & 0 \\
\hline Q7 & 3.52 & 2.782 & 6.302 & 7 & 92 & 99 & 0.503 & 0.03 & 16.632 & 0 \\
\hline Q8 & 3.21 & 2.478 & 5.688 & 7 & 92 & 99 & 0.459 & 0.027 & 17.023 & 0 \\
\hline Q9 & 2.616 & 2.458 & 5.074 & 7 & 92 & 99 & 0.374 & 0.027 & 13.988 & 0 \\
\hline Q10 & 2.674 & 3.128 & 5.802 & 7 & 92 & 99 & 0.382 & 0.034 & 11.235 & 0 \\
\hline Q11 & 2.044 & 2.942 & 4.986 & 7 & 92 & 99 & 0.292 & 0.032 & 9.133 & 0 \\
\hline Q12 & 3.364 & 2.362 & 5.726 & 7 & 92 & 99 & 0.481 & 0.026 & 18.717 & 0 \\
\hline Q13 & 3.58 & 2.812 & 6.392 & 7 & 92 & 99 & 0.511 & 0.031 & 16.73 & 0 \\
\hline Q14 & 3.737 & 2.613 & 6.35 & 7 & 92 & 99 & 0.534 & 0.028 & 18.79 & 0 \\
\hline
\end{tabular}

Graphs obtained by considering rating for the questionnarie taken on $\mathrm{x}$ axis and no.of input samples taken on $\mathrm{y}$ axis 


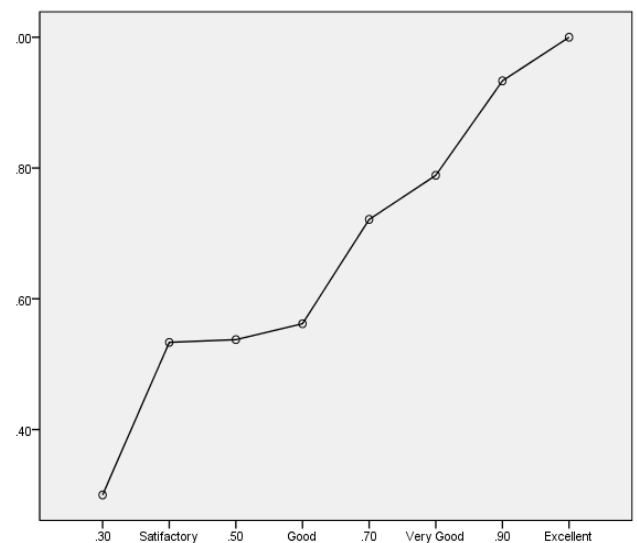

Figure 2. Graph plotted for question 1 considering rating on $\mathrm{x}$ axis rating on $\mathrm{x}$ axis and no. of input samples on y axis

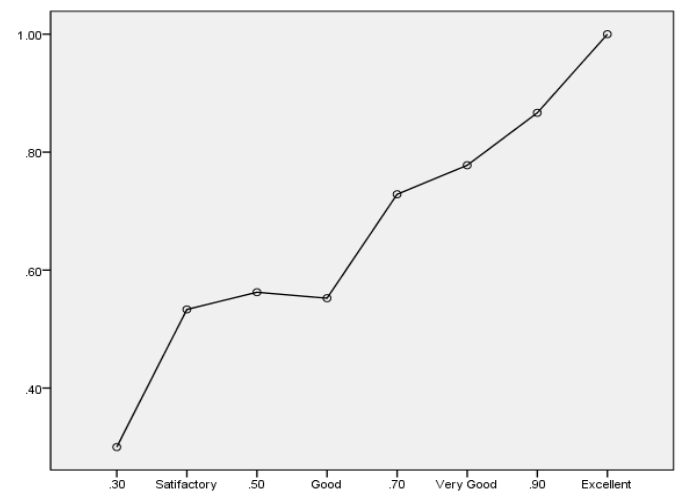

Figure 4. Graph plotted for question 3 considering rating on $\mathrm{x}$ axis on $\mathrm{x}$ axis and no.of input samples on $\mathrm{y}$ axis

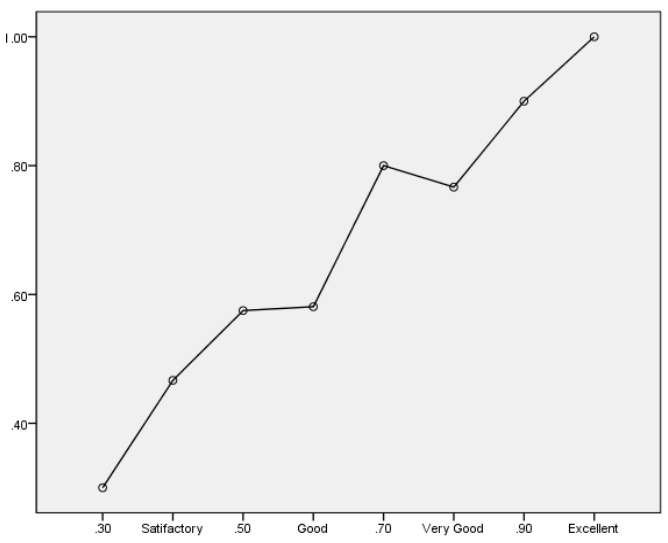

Figure 3. Graph plotted for question 2 considering and no.of input samples on y axis

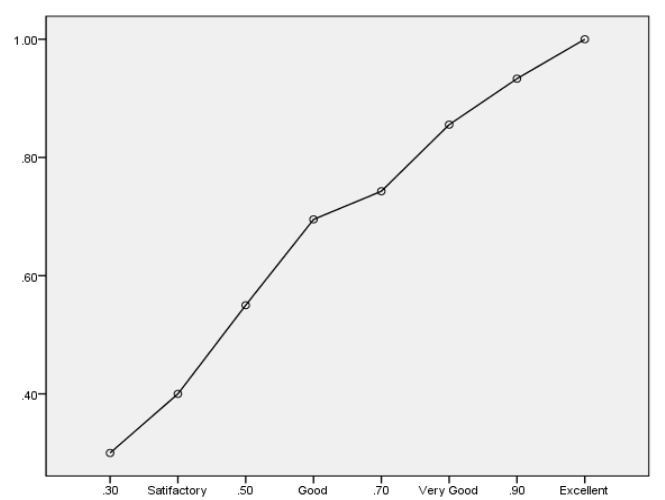

Figure 5. Graph plotted for question 4 considering rating and no.of input samples on y axis

\subsection{Neural Network Model (Training)}

Table 2. Values considered for different parameters for training neural network model

\begin{tabular}{lc}
\hline Training Parameters & Value \\
\hline Momentum Rate & 0.7 \\
Learning Rate & 0.5 \\
Maximum Error & 0.01 \\
Maximum Individual Unit Error & 0.001 \\
No. of max Iterations & 500 \\
No of Outputs & 1 \\
Total No of Inputs & 15 \\
No of hidden layers & 1 \\
\hline
\end{tabular}


Table 3. Normalized System Error obtained on training the neural network model for different no. of input samples considered

\begin{tabular}{|c|c|c|c|c|c|c|c|c|c|c|}
\hline \multirow{2}{*}{$\begin{array}{c}\text { No.of } \\
\text { input } \\
\text { samples }\end{array}$} & \multicolumn{10}{|c|}{ Normalized System Error(NSE) } \\
\hline & Neuron 1 & Neuron 2 & Neuron 3 & Neuron 4 & Neuron 5 & Neuron 6 & Neuron 7 & Neuron 8 & Neuron 9 & Neuron 10 \\
\hline 10 & 0.07 & 0.007 & 0.006 & 0.006 & 0.066 & 0.006 & 0.007 & 0.008 & 0.006 & 0.006 \\
\hline 20 & 0.09 & 0.009 & 0.008 & 0.009 & 0.008 & 0.009 & 0.009 & 0.009 & 0.009 & 0.009 \\
\hline 30 & 0.0769 & 0.067 & 0.076 & 0.067 & 0.067 & 0.067 & 0.067 & 0.067 & 0.067 & 0.066 \\
\hline 40 & 0.059 & 0.059 & 0.059 & 0.050 & 0.050 & 0.050 & 0.050 & 0.050 & 0.050 & 0.050 \\
\hline 50 & 0.089 & 0.089 & 0.089 & 0.089 & 0.080 & 0.080 & 0.080 & 0.080 & 0.080 & 0.080 \\
\hline 60 & 0.074 & 0.067 & 0.075 & 0.067 & 0.075 & 0.067 & 0.067 & 0.066 & 0.067 & 0.067 \\
\hline 70 & 0.066 & 0.066 & 0.066 & 0.066 & 0.057 & 0.057 & 0.057 & 0.057 & 0.057 & 0.057 \\
\hline 80 & 0.059 & 0.059 & 0.050 & 0.050 & 0.050 & 0.050 & 0.050 & 0.050 & 0.050 & 0.050 \\
\hline 90 & 0.055 & 0.055 & 0.045 & 0.045 & 0.045 & 0.044 & 0.044 & 0.044 & 0.044 & 0.044 \\
\hline 100 & 0.075 & 0.067 & 0.077 & 0.063 & 0.066 & 0.066 & 0.064 & 0.066 & 0.066 & 0.066 \\
\hline
\end{tabular}

\subsection{Testing}

Table 4. Results obtained on testing the neural network for different samples

\begin{tabular}{cccc}
\hline Sample Number & Network Generated value & Desired Value & Accuracy \\
\hline 1 & 0.66 & 0.8 & 82.5 \\
2 & 0.66 & 0.7 & 94.2 \\
3 & 0.66 & 0.7 & 94.2 \\
4 & 0.67 & 0.7 & 96.7 \\
5 & 0.67 & 0.9 & 75.2 \\
6 & 0.67 & 0.8 & 84.6 \\
7 & 0.67 & 0.7 & 96.7 \\
8 & 0.67 & 0.8 & 84.6 \\
9 & 0.67 & 0.7 & 96.7 \\
10 & 0.88 & 0.9 & 98.4 \\
\hline
\end{tabular}

\section{DISCUSSION}

We describe the development of a prototype Multi-Layer Perceptron Neural Network model, which had been trained by back propagation algorithm to predict the performance of an educational institute. Although in principle, similar results may be obtained using a variety of statistical methods such as logistic regression and are under the receiver operating characteristic curve, the current method has the advantage of giving dynamic output as more data is generated and fed to it. It also has the advantage of not requiring skills and insight needed to perform and analyze results from sophisticated statistical techniques. In fact, this is the first step in developing such a neural network system which can be trained and predicted as more data is available on an educational domain. Neural network models have been employed in a variety of domains, but to our knowledge this is the first time they are being used to assess the performance of an educational institute [1]. As more data is available, the system improves in precision with respect to accuracy and can be widely employed in different domains on educational front.

\section{CONCLUSION}

We have developed a prototype Neural Network model to assess the performance of an educational institute given the data from an educational domain. Although, a prototype model has been developed, this model can be enhanced to any desired level by increasing the number of input samples. This model can also be applied in wide variety of applications given the incomplete dataset.

\section{REFERENCES}

[1] Barnes T., Desmarais M., Romero C., Ventura S. (2009). Educational Data Mining 2009: 2nd International Conference on Educational Data Mining, Proceedings. Cordoba, Spain. 
[2] Cristobal Romero, Sebastian Ventura "Educational Data Mining: A Review of the State -of-the-Art", IEEE Transactions on Systems, Man and Cybernetics, Vol. XX, No. X, 200X, Pg: 1-21.

[3] Brijesh Kumar Baradwaj, Saurabh Pal, "Mining Educational Data to Analyze Students Performance", International Journal of Advanced Computer Science and Applications, Vol. 2, No. 6, 2011, Pg. No: 63-66

[4] Dr. P.K. Srimani, Mrs. Malini M. Patil, "Regression Modeling on EDU-DATA in Technical Education Systems", International Journal of Advanced Scientific and Technical Research, Issue 3 volume 1, January-February 2013, Pg. No: $320-336$

[5] Romero, C.et al, "Data mining in course management systems: Moodle case study and tutorial", Computers \& Education (2007), doi: 10.1016/j.compedu.2007.05.016

[6] Elakia, Gayathri, Aarthi, Naren J, "Applications of Data Mining in Educational Database for predicting Behavioural Patterns of the Students", International Journal of Computer Science and Information Technology, Vol. 5(3), 2014, 4649-4652.

[7] Mohammed M. Abu Tair, Alaa M. El-Halees, "Mining Educational Data to Improve Students Performance: A case study", International Journal of Information and Communication Technology Research, Volume 2 No. 2, 2012.

[8] Han J., Kamber M. (2006). Data Mining: Concepts and Techniques, Morgan Kaufmann Publishers.

[9] Romero C., Ventura S. (2007). Educational Data Mining: a Survey from 1995 to 2005. Expert Systems with Applications, 1, 33, 135-146.

[10] Romero C. Ventura, S., Pechenizkiy M., Bake, R. (2010). Handbook of Educational Data Mining Taylor \& Francis.

[11] Psaromiligkos Y., Orfanidou M. Kytagias C., Zafiri E. (2009). Mining log data for the analysis of learners' behaviour in web-based learning management systems. In Operational Research Journal, 1-14.

[12] Yu P., Own C., Lin L. (2001). On learning behavior analysis of web based interactive environment. In International Conference on Computer and Electrical Engineering, Oslo/Bergen, Norway, 1-9.

[13] Beal C.R. and Cohen P.R. (2008). Temporal Data Mining for Educational Applications. In Proceedings of the 10th Pacific Rim international Conference on Artificial intelligence: Trends in Artificial intelligence, Hanoi, Vietnam, 66-77.

[14] Feng, M. Beck., J.E., Heffernan N.T. (2009). Using Learning Decomposition and Bootstrapping with Randomization to Compare the Impact of Different Educational Interventions on Learning. In International Conference on Educational Data Mining, Cordoba, Spain, 51-60.

[15] Manda R. Narasinga Rao, G.R. Sridhar, K. Madhu, Allam Appa Rao, "A clinical decision support system using multilayer perceptron neural network to predict wellbeing in diabetes", Journal of Association of Physicians of India, February, 2009, Pg. No: 127-33 